\title{
Effects of number of pellets per food delivery and pellet sucrose composition on schedule-induced drinking
}

\author{
ROBERT W. SCHAEFFER and MICHAEL E. BRUSH \\ Auburn University, Auburn, Alabama 36830
}

\begin{abstract}
Four groups of four rats were tested on a fixed-time (FT 60-sec) schedule in which one, three, or five pellets per food delivery and $0 \%, 8 \%, 16 \%$, and $32 \%$ sucrose pellets were factorially combined. The results showed no statistically significant differences in water intake associated with sucrose content of the pellets, but did show a significant inverse relationship between water intake and number of pellets given per reinforcement. This latter finding was interpreted as a result of the direct relationship in the rat between total number of reinforcement opportunities and probability of drinking. This relationship was suggested to be an important dependent variable in studies that measure and attempt to account for collateral fluid ingestion.
\end{abstract}

Schedule-induced polydipsia (SIP) denotes excessive fluid intakes produced in animals through concurrent placement under a regimen of food deprivation and exposure to fluids and certain schedules of intermittent food delivery (e.g., Falk, 1969, 1971). The development and maintenance of SIP are responsive, in part, to quantitative (e.g., Falk, 1967; Flory, 1971) and qualitative (e.g., Christian \& Schaeffer, 1973b; Colotla \& Keehn, 1975) variations in food composition. Recently, the influence on SIP of manipulating the sugar concentration of the dry-food pellets typically employed in SIP studies has received attention; nonetheless, the nature, degree, and directionality of the influence of pellet sugar content on SIP remain enigmatic. For example, though both Christian and Schaeffer (1973b) and Colotla and Keehn (1975) reported an inverse, ordered relationship between the level of SIP and the percent sugar concentration of Noyes food pellets, Christian and Schaeffer (1973b) found greater water intakes for sugarless pellets than for sugared pellets, whereas Colotla and Keehn (1975) reported exactly the opposite results.

The present experiment was designed, first, to reexamine the effects of food-pellet sucrose concentration on SIP by systematically replicating Christian and Schaeffer's (1973b) study and, second, to determine any possible interaction between food-pellet sucrose content and number of pellets delivered per reinforcement opportunity.

\section{METHOD}

\section{Subjects}

Sixteen experimentally naive Sprague-Dawley female albino rats, approximately 120 days old at the onset of experimenta-

Reprints may be obtained from Robert W. Schaeffer, Department of Psychology, Auburn University, Auburn, Alabama 36830. tion, were used. The animals, randomly assigned to four equal groups, were maintained at approximately $85 \%$ of their freefeeding weights throughout the experiment. Water was always freely available to the animals in both the test chamber and home cage.

\section{Apparatus}

Four Lehigh Valley Electronics two-lever operant chambers (Model 132-02), modified by the removal of the right lever to allow for the insertion of a drink tube, were used. The spout of the drink tube was held in place by a plastic positioning collar, slightly recessed behind the chamber's intelligence panel and located $7 \mathrm{~cm}$ to the right of the food magazine and $3.5 \mathrm{~cm}$ from the chamber floor. Standard relay circuitry was used to program the experimental conditions and to sense and record licks and pellet deliveries. Chamber water intakes were determined after each daily session by converting the difference between pre- and postsession water-bottle weights to milliliters.

\section{Procedure}

The experiment consisted of seven phases (ABCBDBA): (1) baseline, (2) fixed-time (FT) 60-sec schedule with one pellet per food delivery, (3) FT 60 -sec schedule with three pellets per food delivery, (4) FT 60 -sec schedule with one pellet per food delivery, (5) FT 60-sec schedule with five pellets per food delivery, (6) FT 60-sec schedule with one pellet per food delivery, and (7) baseline. Each phase continued until each animal's water intake had stabilized. Stability was defined for all phases as the difference between the total intakes of the last three and previous three test sessions being less than $10 \%$ of the total intake of the last six sessions (cf. Schoenfeld, Cumming, \& Hearst, 1956).

During the baseline phases of the experiment, test sessions consisted of 60 food pellets placed in the food magazine of the experimental chamber, with the animals remaining in the chamber for $60 \mathrm{~min}$.

During Phases 2 through 6, the food cup was empty when each animal was placed in the chamber, and each animal received food pellets on a response-independent FT schedule of food delivery (FT 60-sec) under which food deliveries occurred every $60 \mathrm{sec}$, irrespective of the animals' behavior. During Phases 2, 4, and 6, each food magazine operation delivered one food pellet. During Phase 3, each food delivery consisted of three food pellets, and during Phase 5, each food delivery consisted of five food pellets. During Phases 2 through 6, session length was held constant at $60 \mathrm{~min}$, and the number of food deliveries per test session was held constant at 60 . 
During all phases of the experiment, Group 1 received sugarless $45-\mathrm{mg}$ Noyes food pellets (Formula $A$, without the $7.5 \%$ glucose binder, cf. Christian \& Schaeffer, 1973a), while Groups 2, 3, and 4 received food pellets identical to those received by Group 1, except for the addition, by weight, of $8 \%, 16 \%$, and $32 \%$ sucrose, respectively.

\section{RESULTS}

Mean group water intakes obtained during all seven phases of the experiment are presented in Figure 1. Relative to the initial baseline condition, the introduction of spaced food deliveries produced polydipsic water intakes in all groups. In our laboratory, polydipsia is defined as no less than a $200 \%$ fluid intake increase in the experimental condition, relative to the initial baseline condition (Christian, Schaeffer, \& King, 1977). The polydipsic intakes were maintained during all the FT 60-sec condition phases, irrespective of betweengroup differences in food-pellet composition and between-phase differences in food-delivery magnitude. A visual comparison within experimental phases of the mean group water intakes indicated that (1) during both the initial and final baseline phases, there were no apparent differences in mean water intakes of the four groups and (2) during the FT 60 -sec condition phases, the relation between the groups' water intakes was apparently dependent on the magnitude of food delivery. Further visual inspection of the mean group water intakes during the FT 60-sec phases revealed: (1) During the initial one-pellet food-delivery condition, the sugarless-pellet group drank more than did the groups receiving pellets containing sucrose. (2) The increase in food-delivery magnitude from one to three pellets per food delivery did not substantially affect the water intakes of any of the sucrose-pellet groups but did dramatically reduce the sugarless-pellet group's water intakes to a level congruent with those of the sucrosepellet groups. (3) The reinstatement of the one-pellet food-delivery condition produced water intakes in all groups similar in degree and relation to the values obtained in the original one-pellet condition. (4) The introduction of the five-pellet food-delivery condition resulted in decreased water intakes for all groups, relative to both the one- and three-pellet food-delivery conditions, with no between-group differences in water intake being evident. (5) The second reinstatement of the one-pellet food deliveries increased all groups' water intakes, relative to the five-pellet food deliveries. During the second reinstatement of the one-pellet food deliveries, the sugarless and $16 \%$ and $32 \%$ sucrose groups recovered their previous one-pellet food-delivery waterintake levels, while the $8 \%$ sucrose group demonstrated terminal water intakes greater than those obtained during both previous one-pellet conditions and those of the other sucrose groups during that condition (Phase 6).

In order to determine whether these graphically apparent between-group and between-phase differences

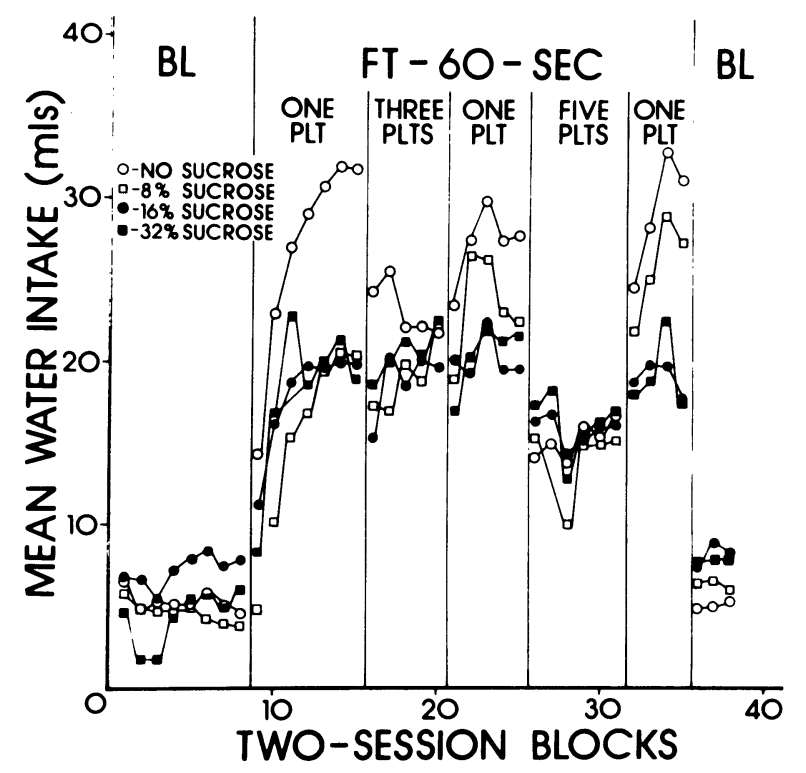

Figure 1. Mean group water intakes in milliliters for all seven phases of the experiment. Each data point represents average group intakes across two consecutive daily test sessions.

in mean water intake were statistically significant, a repeated-measures analysis of variance was applied to the water intakes obtained from all animals during the last six sessions of each experimental phase. Due to extreme within-group variance, the difference between groups was not significant $(F=.42, \mathrm{df}=3 / 12, \mathrm{p}>.05)$; however, there was a significant difference between phases $(F=33.31$, $d f=6 / 72, p<.01)$. A determination of the loci of between-phase (i.e., food-delivery magnitude condtions) differences was made by applying a new multiple-range test $(p<.01)$ to the mean water intakes of all phases. The results of the test revealed that (1) water intakes during all FT 60 -sec conditions significantly exceeded those during both baseline conditions and (2) there were no significant differences in water intakes between the two baseline conditions. With respect to the FT $60-\mathrm{sec}$ conditions, the postANOVA test indicated that (1) there were no significant differences in water intake between the one-pellet fooddelivery conditions used in Phases 2, 4, and 6, (2) water intakes obtained in the three-pellet condition did not differ significantly from those produced by all three one-pellet conditions, and (3) the five-pellet fooddelivery condition water intakes were significantly less than those obtained in all three one-pellet conditions but did not differ significantly from the three-pellet condition water intakes.

In order to determine whether the food-delivery magnitude manipulation had differentially affected the experimental groups, repeated-measures analyses of variance were applied to the water intakes of each group's animals from the last six sessions of each experimental phase. The results of the four ANOVAs 
indicated that there were significant between-phase differences $(p<.01)$ for all groups. The subsequent application of multiple-range tests $(p<.01)$ to each group's mean phase water intakes, however, indicated that the between-phase differences were not the same for all groups. Relative to the initial one-pellet fooddelivery condition, the three-pellet condition produced a significant decrease in water intake for only the sugarless group, but the five-pellet condition produced significant decreases in all four groups' water intakes. Reintroduction of the one-pellet condition in Phases 4 and 6 produced recoveries of the Phase 2 water-intake levels in all groups.

\section{DISCUSSION}

The results of the present experiment, in general, support the findings of previous research with respect to both the effects of food-delivery magnitude and sugar composition of the food pellet on schedule-induced drinking. The decrement in total sessional drinking found to be associated with the increased amount of food delivered per reinforcement in the present study has previously been reported by Falk (1967) and by Freed and Hymowitz (1972), who found that increments and decrements in the size of food deliveries produced inverse changes in total milliliters drunk per session. It should be noted, however, that Flory (1971) and Hawkins, Everett, Githens, and Schrot (1972) have reported no decrement in amount drunk per reinforcement as a function of number of pellets earned per reinforcement, even when quantity of reinforcement is shown simultaneously to be inversely related to total milliliters drunk per session. This apparently anomalous finding is due to the fact that if session length, schedule of reinforcement, and number of pellets given per session are all held constant, while number of pellets given per reinforcement opportunity is varied, the total number of reinforcement opportunities available to the animal in a session is inversely related to number of pellets given per reinforcement. Thus, if session length is held constant at $60 \mathrm{~min}$ for a FT $60-\mathrm{sec}$ schedule, and the total number of pellets given per session is also held constant at 60 , then one pellet per reinforcement produces 60 reinforcement opportunities equally distributed throughout the hour test session, whereas five pellets per reinforcement produce only 12 reinforcement opportunities, all of which are realized during only the first $12 \mathrm{~min}$ of a test session which will continue for another $48 \mathrm{~min}$, but without any further reinforcement opportunities. If foodcorrelated water ingestion in the rat were perfectly correlated with the termination of an eating episode, then in the onepellet per reinforcement condition cited above the rat would be expected to commence drinking 60 times, whereas in the fivepellet per reinforcement condition the rat would be expected to initiate food-correlated drinking only 12 times. Unfortunately, although food-correlated drinking does occur in the rat, this relationship is less than perfect for individual rats, and even less predictable as an average group phenomenon in rats. Although the present study was not instrumented to measure eat-drink correlations in either the individual or group case, observation suggested that previous reports of eat-drink correlations decreasing across sessions are correct (cf. Christian, Schaeffer, \& King, 1977). Further, as was originally shown by Shumake (1968) and as has recently been replicated by Christian, Schaeffer, and King (1977) and Schaeffer (1977), when the rat does drink following food delivery, it typically emits a lick burst that ranges in length from 90 to 225 licks. SIP is, thus, apparently primarily the result of an increase in frequency of Irinking bouts that reinforcement schedule manipulations produce. Aithough none of the data collected in this experiment appeared to contradict that inference, specific studies need to be done to carefully examine this possibility.

With respect to food-delivery composition, previous researchers have generally reported ordinal relations, but not always reliable statistically significant differences, in the level of SIP produced in between-groups experiments using sugared and sugarless pellets. The present experiment's results are congruent with those of Christian (1975), Christian, Riester, and Schaeffer (1973), and Christian and Schaeffer (1973b, 1975), who reported that the addition of sucrose and/or glucose to dryfood pellets produced a numerical attenuation in scheduleinduced drinking. Although the present study revealed no statistically significant differences between the sugarless and sucrose groups' water intakes, numeric trends, suggestive of the earlier numeric relation between sugared pellets and SIP, were evident. Future research relating SIP to food-pellet composition might profitably compare within-subject and betweengroup designs, not only because of the extreme between-subject variability in water intakes found in most SIP studies (cf. Brush \& Schaeffer, 1974) or because of the dramatic effect that within-subject variations in pellet composition have upon collateral fluid intake (cf. Falk, 1967), but also because the present experiment demonstrated an interactive effect between the number of pellets dispensed per reinforcement opportunity and the composition of the food pellet upon SIP.

Previous explanations of the numerically suggestive, but statistically suspect, inverse group relationships obtained between sugar concentration and schedule-induced drinking have focused on frustrative nonreward theory (cf. Christian, 1974; Denny \& Ratner, 1970). This theory maintains that SIP is a form of displaced consummatory activity elicited by the aversive properties of the SIP paradigm, such as spaced feeding and meager food-delivery magnitudes. Inherent in this theory is the assumption that certain manipulations, such as increasing the sugar content of the food pellet, will significantly reduce the frustrative aspects of intermittent food schedules and will, consequently, attenuate SIP. Sucrose concentration of Noyes pellets has been shown to be a potent variable affecting group rates of acquisition and extinction of barpressing in rats (Schaeffer \& Hanna, 1966). However, thus far there is precious little evidence from between-group experiments to suggest that collateral fluid intake is differentially affected by sugar content of the food pellet in any predictable fashion. Further, relative to the large within-group effects upon SIP that are consistently shown by type of reinforcement schedule used, composition and type of food used, and type of collateral fluid offered for drinking (cf. Christian, Schaeffer, \& King, 1977), the modest ordinal relations sometimes found between groups offered pellets of differing sucrose content and SIP suggest that the sugar variable in isolation is not a potent determinant of SIP.

\section{REFERENCES}

Brush, M. E., \& Schaeffer, R. W. Effects of water deprivation on schedule-induced polydipsia. Bulletin of the Psychonomic Society, 1974, 4, 69-72.

Christian, W. P. Investigations of schedule-induced polydipsia as an example of displaced consummatory activity elicited by frustration. Unpublished doctoral dissertation, Auburn University, 1974.

Christian, W. P. Interactive effects of interpellet interval and pellet composition on schedule-induced licking and drinking behavior. Bulletin of the Psychonomic Society, 1975, 5 , 122-124.

Christian, W. P., Reister, R. W., \& Schaeffer, R. W. Effects of sucrose concentrations upon schedule-induced polydipsia using free and response-contingent dry-food 
reinforcement schedules. Bulletin of the Psychonomic Society, 1973, 2, 65-68.

Christian, W. P., \& Schaeffer, R. W. Note: Advisability of using sugarfree food pellets for schedule-induced polydipsia research. Psychological Reports, 1973, 32, 274. (a)

Christian, W. P., \& Schaeffer, R. W. Effects of sucrose concentrations upon schedule-induced polydipsia on a FFI60-sec dry-food reinforcement schedule. Psychological Reports, 1973, 32, 1067-1073. (b)

Christian, W. P., \& Schaeffer, R. W. Motivational properties of fixed-interval reinforcement. Bulletin of the Psychonomic Society, 1975, 5, 143-145.

Christian, W. P., Schaeffer, R. W., \& King, G. D. Schedule-induced behavior: Research and theory. Montreal: Eden Press, 1977.

Colotla, V. A., \& KeEHN, J. D. Effects of reinforcer-pellet composition on schedule-induced polydipsia with alcohol, water, and saccharin. Psychological Record, 1975, 25, 91-98.

DenNy, M. R., \& RATNer, S. C. Comparative psychology. Homewood, Ill: Dorsey, 1970.

FALK, J. L. Control of schedule-induced polydipsia: Type, size, and spacing of meals. Journal of the Experimental Analysis of Behavior, 1967, 10, 199-206.

FALK, J. L. Conditions producing psychogenic polydipsia in animals. Annals of the New York Academy of Science, 1969, 157, 569-593.

FALK, J. L. The nature and determinants of adjunctive behavior. Physiology and Behavior, 1971, 6, 577-588.
FloRY, R. K. The control of schedule-induced polydipsia: Frequency and magnitude of reinforcement. Learning and Motivation, 1971, 2, 215-227.

Freed, E. X., \& Hymowitz, N. Effects of schedule, percent body weight, and magnitude of reinforcer on acquisition of schedule-induced polydipsia. Psychological Reports, 1972. 31. 95-101.

Hawkins, T. D., Everett, P. B., Githens, S. H., \& Schrot, J. F. Schedule-induced polydipsia: An analysis of water and alcohol ingestion. In R. M. Gilbert \& J. D. Keehn (Eds.), Schedule effects: Drugs, drinking, and aggression. Toronto: University of Toronto Press, 1972. Pp. 95-128.

Schaeffer, R. W. The response of desalivate rats to a timedependent food reinforcement schedule. Physiology and Behavior, 1977, 18, 895-899.

SChaEffer, R. W.. \& HANnA, B. Effects of quality and quantity of reinforcement upon response rate in acquisition and extinction. Psychological Reports, 1966, 18, 819-829.

Schoenfeld, W. N., Cumming, W. W., \& Hearst, E. On the classification of reinforcement schedules. Proceedings of the National Academy of Sciences, 1956, 42, 563-570.

Shumake, R. A. B. Schedule-induced polydipsia: Licking response patterns associated with concurrently available fluids. Unpublished master's thesis, Florida State University, 1968.

(Received for publication February 9, 1978.) 